\title{
Mengkaji Kelengkapan Human Factors Analysis And Classification System (HFACS) dari Sisi Budaya berdasarkan Dimensi Budaya dari Trompenaars
}

\author{
Iftikar Z. Sutalaksana, Edwina Dwi Sadika \\ Fakultas Teknologi Industri, Program Studi Teknik Industri, ITB \\ Jl. Ganesa 10 Bandung 40132 \\ Email: siftikar@y7mail.com, edwinasadika@gmail.com
}

\begin{abstract}
ABSTRAK
Human Factor Analysis and Classification System (HFACS) merupakan alat untuk mengidentifikasi kesalahan manusia pada suatu aktivitas. HFACS diduga memerlukan penambahan aspek budaya sesuai dengan yang berlaku di negara HFACS tersebut akan diterapkan. Penambahan aspek budaya tersebut akan membuat HFACS mampu mengidentifikasi aspek budaya yang mempengaruhi kecelakaan. Faktor penyebab kecelakaan penerbangan diklasifikasikan dengan HFACS dan aspek budaya yang memengaruhinya diidentifikasi dengan dimensi budaya dari Trompenaars. Dengan dukungan hasil wawancara dan pengolahan data, dapat diidentifikasi hubungan lapisan HFACS dengan aspek budaya. Analisis mengenai kebutuhan aspek budaya pada setiap lapisan HFACS pun dilakukan untuk mengevaluasi kandungan aspek budaya dalam HFACS dan menentukan apakah HFACS perlu ditambahkan aspek budaya. Persentase lapisan HFACS yang terlibat dalam kecelakaan penerbangan yang diteliti adalah Precondition for Unsafe Acts (34\%), Unsafe Acts (32 \%), Organizational Influences (19\%), dan Unsafe Supervision (15\%). Sedangkan sub lapisan HFACS yang paling dominan menjadi penyebab kecelakaan adalah Skill Based Errors (15,57\%). Dimensi Universalism vs Particularism adalah dimensi budaya yang paling sering ditemukan sebagai penyebab kecelakaan. Pada HFACS awal, beberapa aspek budaya telah termasuk pada lapisan tertentu seperti Precondition for Unsafe Acts. Sementara lapisan yang perlu dipertimbangkan untuk dilengkapi dengan aspek budaya adalah Unsafe Acts-Decision Error, Unsafe Supervision, dan Organizational Influences - Organizational Process.
\end{abstract}

Kata kunci: faktor manusia, HFACS, dimensi budaya, Trompenaars

\section{Pendahuluan}

Human Factor Analysis and Classification System (HFACS) merupakan alat untuk mengidentifikasi faktor manusia yang dikembangkan oleh Shappell \& Wiegmann (2001). HFACS dibentuk berdasarkan swiss cheese model yang sebelumnya dikembangkan oleh Reason pada tahun 1990. Swiss cheese model menunjukkan bahwa kecelakaan dapat terjadi akibat beberapa faktor atau kejadian yang saling berhubungan. Faktor-faktor tersebut terbagi atas empat klasifikasi yaitu Organizational Influence, Unsafe Supervision, Preconditions for Unsafe Acts, dan Unsafe Acts. Sub lapisan HFACS secara lebih jelas dapat dilihat pada Gambar 1. 


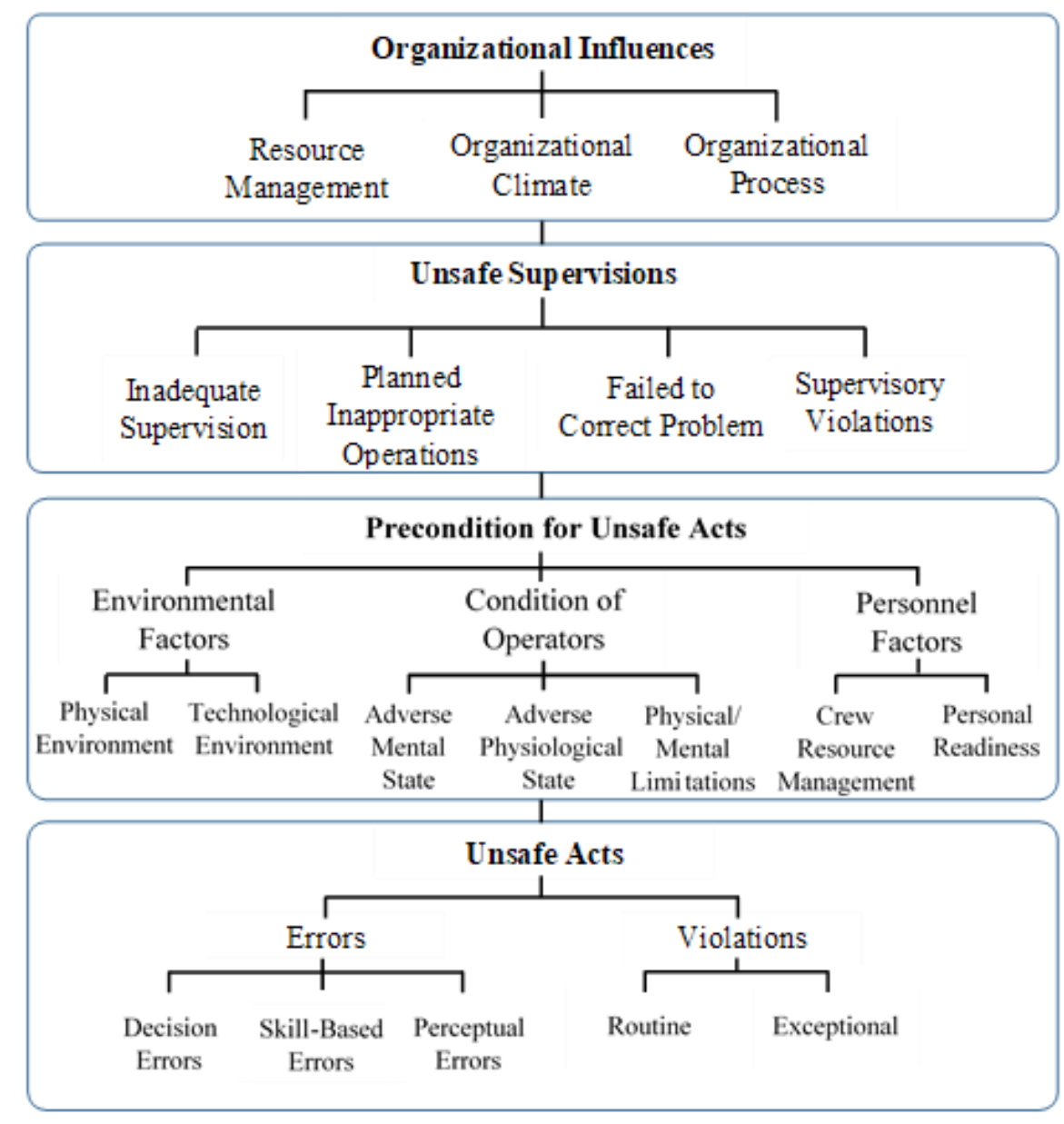

Gambar 1. Taksonomi HFACS (Shappell et al., 2007)

HFACS dapat digunakan untuk melakukan investigasi pada berbagai kecelakaan transportasi maupun insiden lainnya secara umum. Bahkan HFACS dapat dikembangkan untuk kejadian kesalahan praktek operasi di lingkungan medis dan kecelakaan pertambangan. Walau begitu, HFACS pada awalnya dikembangkan untuk kecelakaan transportasi udara. Oleh karena itu, HFACS banyak digunakan untuk lingkungan penerbangan. HFACS dapat menunjukkan penyebab kecelakaan penerbangan dapat melibatkan faktor manusia dari berbagai sisi bukan hanya kesalahan pelaku langsung di pesawat. HFACS dapat digunakan untuk melakukan invetigasi kecelakaan penerbangan yang dikarenakan manusia, menganalisis pola penyebab kecelakaan, dan mengidentifikasi penyebab kecelakaan yang dominan.

Setiap faktor manusia dapat muncul akibat pengaruh budaya yang berlaku bagi orang yang bersangkutan. Perilaku orang Indonesia dipengaruhi oleh budaya yang berlaku di Indonesia. Untuk itu, setiap faktor manusia yang muncul dalam suatu kecelakaan penerbangan di Indonesia pun dipengaruhi oleh aspek budaya Indonesia. Dimensi budaya yang dominan dan memengaruhi munculnya faktor manusia yang menyebabkan kecelakaan penerbangan perlu diketahui untuk mengantisipasi faktor manusia tersebut dan perbaikan keselamatan penerbangan. Berdasarkan penelitian yang dilakukan oleh Paletz (2009), HFACS memerlukan modifikasi. Menurut Li et al (2007), budaya dapat mempengaruhi kecelakaan. Oleh karena itu, HFACS diduga memerlukan aspek budaya sesuai dengan budaya yang berlaku di negara HFACS tersebut akan diterapkan. Penambahan aspek budaya tersebut akan membuat HFACS mampu mengidentifikasi aspek budaya yang mempengaruhi kecelakaan.

Tingkat kecelakaan penerbangan semakin meningkat dari tahun ke tahun. Hal ini sangat disayangkan mengingat kebutuhan masyarakat Indonesia terhadap transportasi udara pun semakin meningkat. Untuk melakukan pencegahan atau antisipasi terhadap kemungkinan kecelakaan penerbangan perlu diketahui terlebih dahulu aspek budaya dari penyebab-penyebab utama dari kecelakaan penerbangan. Sebuah kecelakaan penerbangan dapat disebabkan oleh beberapa faktor dan melibatkan berbagai pihak. Penelitian ini ingin menemukan dimensi budaya apa yang dominan mempengaruhi faktor penyebab dibalik terjadinya kecelakaan penerbangan di Indonesia. Metode yang digunakan untuk mengetahui faktor penyebab utama kecelakaan adalah HFACS (Human Factors Analysis and Classification System), sementara untuk menganalisis aspek budaya digunakan dimensi budaya dari Trompenaars. 
Dimensi budaya dari Trompenaars antara lain:

a. Universalism vs Particularism (UP)

Dimensi budaya universalism memiliki karakteristik yang mementingkan peraturan dan hukum dalam membangun suatu hubungan, perjanjian, dan persetujuan. Sementara penganut particularism memiliki karakteristik untuk menentukan apa yang benar dan apa yang salah berdasarkan situasi yang terjadi dan siapa yang terlibat. Dengan begitu, perjanjian pun dapat berubah-ubah sesuai situasi.

b. Individualism vs Collectivism (IC)

Individualism merupakan dimensi budaya yang mementingkan kebebasan dan pencapaian pribadi. Sebaliknya, collectivism mengutamakan pencapaian tujuan kelompok dan tugas tersebut merupakan tanggung jawab bersama.

c. Neutral vs Affective Relationship (NA)

Penganut budaya neutral akan berusaha keras untuk mengontrol emosi dan menyembunyikan pemikiran atau perasaan mereka. Sementara penganut budaya affective memiliki karakterstik untuk menunjukkan emosi bahkan secara spontan.

d. Specific vs Diffuse (SD)

Fokus pada tujuan dan tidak berbelit-belit merupakan salah satu karakteristik budaya specific. Bagi penganut budaya diffuse, pekerjaaan dan kehidupan pribadi tidak sepenuhnya terpisah. Selain itu, penganut budaya specific pun menganggap pekerjaan dan kehidupan pribadi adalah hal yang terpisah.

e. Achivement vs Ascription (AA)

Budaya achievement atau ascription adalah budaya yang menunjukkan cara orang dalam memandang status. Orang yang memiliki budaya achievement akan memandang status berdasarkan performansi atau prestasi. Kekuasaan, jabatan, usia, dan posisi dalam sosial sangat menentukan status seseorang pada budaya ascription.

f. $\quad$ Time Orientation (TO)

Budaya sequential time menganggap suatu aktivitas terjadi secara berurutan sehingga dalam satu waktu hanya dapat fokus pada satu aktivitas. Masa lalu, saat ini, dan masa depan adalah suatu jalinan waktu. Penganut budaya synchronous time dapat melakukan beberapa aktivitas dalam satu waktu dan menganggap rencana adalah hal yang fleksibel.

g. Internal vs External (IE)

Penganut budaya internal direction beranggapan bahwa orang dapat mengontrol dan mempengaruhi lingkungan. Sementara dalam budaya external direction, lingkungan dapat mengontrol dan mempengaruhi seseorang (Trompenaars \& Hampden-Turner, 1997).

Selain itu, dilakukan pula evaluasi kandungan aspek budaya dalam HFACS sehingga dapat ditentukan apakah HFACS perlu ditambahkan aspek budaya agar HFACS sesuai untuk diterapkan di Indonesia.

\section{Metode Penelitian}

Penelitian diawali dengan studi pendahuluan untuk mendapatkan pengetahuan yang lebih mendalam mengenai sistem penerbangan di Indonesia secara umum, kecelakaan penerbangan yang terjadi Indonesia mulai dari jumlah kecelakaan, kronologis kecelakaan, penyebab kecelakaan, hingga kerugian yang ditimbulkan dari kecelakaan tersebut. Studi pendahuluan dapat dilakukan dengan melihat berbagai referensi seperti buku, internet, tugas akhir, dan jurnal terkait kecelakaan transportasi udara. Setelah melakukan studi pendahuluan, dapat dilakukan penetapan rumusan, tujuan, manfaat, dan batasan penelitian. Selain itu, metode penelitian pun ditentukan dan dilakukan studi lebih dalam mengenai HFACS sebagai alat bantu investigasi kecelakaan dan dimensi budaya dari Trompenaars sebagai teori yang digunakan untuk mengidentifikasi aspek budaya.

Penelitian ini menggunakan data sekunder yang berasal dari laporan final hasil investigasi kecelakaan penerbangan yang dipublikasikan oleh KNKT. Data yang digunakan merupakan final report periode 2001-2012 yang diakses melalui http://www.dephub.go.id/knkt/ntsc_aviation/aaic.htm. Klasifikasi faktor penyebab kecelakaan dengan HFACS dilakukan berdasarkan faktor penyebab kecelakaan yang tertera pada laporan final KNKT tersebut. Kemudian aspek budaya yang berhubungan dengan faktor penyebab kecelakaan tersebut diidentifikasi dengan dimensi budaya dari Trompenaars.

Untuk mendukung pengklasifikasian faktor penyebab kecelakaan dengan HFACS dan identifikasi aspek budaya yang berhubungan dengan faktor tersebut, dilakukan wawancara dan penyebaran kuesioner. Dengan wawancara dapat diperoleh informasi umum mengenai sistem penerbangan di Indonesia dan konfirmasi klasifikasi faktor penyebab kecelakaan dengan HFACS dan aspek budaya yang ditemukan. Wawancara dilakukan pada dosen Teknik Penerbangan ITB yang membidangi manajemen keselamatan penerbangan dan sistem transportasi udara, mantan Direktur Utama sebuah perusahaan penerbangan terkemuka, pilot senior maskapai terkemuka, mantan Direktur Niaga sebuah perusahaan penerbangan terkemuka, dan safety personnel sebuah perusahaan penerbangan terkemuka yang merupakan tingkat kedua dan ketiga tertinggi pada manajemen safety. Kuesioner digunakan untuk mengukur dimensi budaya pada salah satu maskapai penerbangan terkemuka di Indonesia. Hasil dari kuesioner tersebut merupakan data pendukung mengenai budaya Indonesia. 
Hasil pengklasifikasian faktor penyebab kecelakaan dengan HFACS dan hasil identifikasi aspek budaya yang berhubungan dengan faktor penyebab kecelakaan dianalisis sehingga dapat ditemukan hubungan setiap lapisan HFACS dengan dimensi budaya dari Trompenaas, dan evaluasi kelengkapan HFACS dari sisi budaya serta penentuan keperluan modifikasi HFACS.

\section{Hasil dan Pembahasan}

Jumlah kecelakaan penerbangan di Indonesia tahun 2001-2012 yang telah diinvestigasi oleh KNKT dan telah diterbitkan laporan finalnya adalah 53 kecelakaan. Dari 53 kecelakaan tersebut, faktor manusia terlibat sebagai penyebab kecelakaan dalam 45 kecelakaan. Dengan kata lain, 84,91\% dari kecelakaan yang diteliti melibatkan faktor manusia sebagai penyebab kecelakaan.

Faktor HFACS yang paling dominan terlibat dalam kecelakaan penerbangan yang diteliti adalah Level Precondition for Unsafe Acts sebesar 34\%. Walau begitu faktor Unsafe Acts pun memiliki frekuensi kemunculan yang tidak jauh berbeda dari Level Precondition for Unsafe Acts yaitu $32 \%$. Sementara level Unsafe Supervision dan Organizational Influences pun tidak jauh berbeda frekuensi kemunculannya yaitu $15 \%$ dan $19 \%$.

Menurut Shappell \& Wiegmann (2001), faktor manusia dapat mempengaruhi kecelakaan penerbangan 70-80\%. Sementara KNKT dapat menemukan 52\% penyebab kecelakaan dari tahun 2007-2011 adalah faktor manusia. Dengan hasil penemuan faktor manusia berkontribusi 84,91\% pada kecelakaan penerbangan dari tahun 2001-2012 atau 82,2\% untuk kecelakaan tahun 2007-2011, HFACS nampaknya mampu menemukan faktor manusia dengan lebih detail.

Sementara itu, sub lapisan HFACS yang paling dominan menjadi penyebab kecelakaan adalah Skill Based Error. Enam urutan sub lapisan HFACS yang paling dominan menjadi penyebab kecelakaan adalah Skill Based Errors (15,57\%), Organizational Process (12,30\%), Crew Resources management (9,43\%), Decision Errror (9,02\%), Adverse Mental States (8,61\%), dan Inadequate Supervision (7,38\%). Pada Tabel 1 dapat dilihat rincian persentase kemunculan setiap sub lapisan HFACS.

Tabel 1. Persentase penyebab insiden/kecelakaan berdasarkan klasifikasi HFACS

\begin{tabular}{|c|c|c|c|c|c|c|}
\hline Level & Sub level & Sub-sub level & Jumlah & Persentase & Jumlah & Persentase \\
\hline \multirow[t]{5}{*}{ Unsafe Acts } & \multirow[t]{3}{*}{ Errors } & Decision Errors & 22 & $9,02 \%$ & \multirow{5}{*}{78} & \multirow{5}{*}{$31,97 \%$} \\
\hline & & Skill Based Errors & 38 & $15,57 \%$ & & \\
\hline & & Perceptual Errors & 10 & $4,10 \%$ & & \\
\hline & \multirow[t]{2}{*}{ Violations } & Routine Violations & 4 & $1,64 \%$ & & \\
\hline & & Exceptional Violations & 4 & $1,64 \%$ & & \\
\hline \multirow{7}{*}{$\begin{array}{l}\text { Preconditions } \\
\text { for Unsafe Acts }\end{array}$} & \multirow{2}{*}{$\begin{array}{l}\text { Environmental } \\
\text { Factors }\end{array}$} & Physical Environment & 16 & $6,56 \%$ & \multirow{7}{*}{82} & \multirow{7}{*}{$33,61 \%$} \\
\hline & & Technological Environment & 14 & $5,74 \%$ & & \\
\hline & \multirow{3}{*}{$\begin{array}{l}\text { Condition of } \\
\text { Operators }\end{array}$} & Adverse Mental States & 21 & $8,61 \%$ & & \\
\hline & & Adverse Physiological States & 0 & $0,00 \%$ & & \\
\hline & & Physical/Mental Limitations & 8 & $3,28 \%$ & & \\
\hline & \multirow{2}{*}{$\begin{array}{l}\text { Personnel } \\
\text { Factors }\end{array}$} & Crew Resource Management & 23 & $9,43 \%$ & & \\
\hline & & Personal Readiness & 0 & $0,00 \%$ & & \\
\hline \multirow{4}{*}{$\begin{array}{l}\text { Unsafe } \\
\text { Supervision }\end{array}$} & \multicolumn{2}{|c|}{ Inadequate Supervision } & 18 & $7,38 \%$ & \multirow{4}{*}{38} & \multirow{4}{*}{$15,57 \%$} \\
\hline & \multicolumn{2}{|c|}{ Planned Inappropriate Operations } & 8 & $3,28 \%$ & & \\
\hline & \multicolumn{2}{|c|}{ Failed to Correct Problem } & 7 & $2,87 \%$ & & \\
\hline & \multicolumn{2}{|c|}{ Supervisory Violations } & 5 & $2,05 \%$ & & \\
\hline \multirow{3}{*}{$\begin{array}{l}\text { Organizational } \\
\text { Influences }\end{array}$} & \multicolumn{2}{|c|}{ Resource Management } & 13 & $5,33 \%$ & & \\
\hline & \multicolumn{2}{|c|}{ Organizational Climate } & 3 & $1,23 \%$ & 46 & $18,85 \%$ \\
\hline & \multicolumn{2}{|c|}{ Organizational Process } & 30 & $12,30 \%$ & & \\
\hline
\end{tabular}

Universalism vs Particularism adalah dimensi budaya yang paling dominan sebagai budaya yang berhubungan dengan penyebab kecelakaan. Selain itu, dimensi Internal vs External Direction adalah dimensi kedua yang paling sering muncul. Dimensi budaya dari Trompenaars lainnya juga diidentifikasi pernah menjadi aspek yang mempengaruhi penyebab kecelakaan walau frekuensinya tidak sebanyak dua dimensi tersebut. 
Rincian hubungan lapisan HFACS dengan dimensi budaya dari Trompenaars dapat dilihat pada Tabel 2. Pada tabel tersebut tercantum frekuensi kemunculan setiap dimensi budaya dari Trompenaars yang berhubungan dengan faktor penyebab kecelakaan yang diklasifikasikan pada sub lapisan HFACS.

Tabel 2. Frekuensi dimensi budaya dan hubungannyadengan sub lapisan HFACS

\begin{tabular}{|c|c|c|c|c|c|c|c|c|c|c|c|c|c|c|c|c|}
\hline \multicolumn{3}{|c|}{ HFACS } & \multicolumn{14}{|c|}{ Dimensi Budaya Trompenaars } \\
\hline \multirow[t]{2}{*}{ Level } & \multirow[t]{2}{*}{ Sub level } & \multirow[t]{2}{*}{ Sub-sub level } & \multicolumn{2}{|c|}{ UP } & \multicolumn{2}{|c|}{ IC } & \multicolumn{2}{|c|}{ NA } & \multicolumn{2}{|c|}{ SD } & \multicolumn{2}{|c|}{ AA } & \multicolumn{2}{|c|}{ TO } & \multicolumn{2}{|c|}{$\mathrm{IE}$} \\
\hline & & & $\mathrm{U}$ & $\mathrm{P}$ & I & $\mathrm{C}$ & $\mathrm{N}$ & A & $\mathrm{S}$ & $\mathrm{D}$ & As & $\mathrm{Ac}$ & SS & PPF & I & $\mathrm{E}$ \\
\hline \multirow[t]{5}{*}{ Unsafe Acts } & \multirow[t]{3}{*}{ Errors } & Decision Errors & & 14 & 3 & & 1 & & & & 3 & & & & 2 & \\
\hline & & Skill Based Errors & & & & & & & & & & & & & & \\
\hline & & Perceptual Errors & & & & & & & & & & & & & & \\
\hline & \multirow[t]{2}{*}{ Violations } & Routine Violations & & 4 & & & & & & & & & & & & \\
\hline & & $\begin{array}{l}\text { Exceptional } \\
\text { Violations }\end{array}$ & & 4 & & & & & & & & & & & & \\
\hline \multirow{7}{*}{$\begin{array}{l}\text { Preconditions } \\
\text { for Unsafe } \\
\text { Acts }\end{array}$} & \multirow[t]{2}{*}{$\begin{array}{l}\text { Environment } \\
\text { al Factors }\end{array}$} & $\begin{array}{l}\text { Physical } \\
\text { Environment }\end{array}$ & & & & & & & & & & & & & & 16 \\
\hline & & $\begin{array}{l}\text { Technical } \\
\text { Environment }\end{array}$ & & & & & & & & & & & & & & 6 \\
\hline & \multirow[t]{3}{*}{$\begin{array}{l}\text { Condition of } \\
\text { Operators }\end{array}$} & $\begin{array}{l}\text { Adverse Mental } \\
\text { States }\end{array}$ & & & & & 1 & 1 & & & 1 & & 6 & & 1 & 4 \\
\hline & & $\begin{array}{l}\text { Adverse } \\
\text { Physiological } \\
\text { States }\end{array}$ & & & & & & & & & & & & & & \\
\hline & & $\begin{array}{l}\text { Physical/Mental } \\
\text { Limitations }\end{array}$ & & 1 & & & & & & 1 & & & & & & \\
\hline & \multirow[t]{2}{*}{$\begin{array}{l}\text { Personnel } \\
\text { Factors }\end{array}$} & $\begin{array}{l}\text { Crew Resource } \\
\text { Management }\end{array}$ & & & 5 & & 7 & & & 5 & 3 & & & & & \\
\hline & & $\begin{array}{l}\text { Personal } \\
\text { Readiness }\end{array}$ & & & & & & & & & & & & & & \\
\hline \multirow{4}{*}{$\begin{array}{l}\text { Unsafe } \\
\text { Supervision }\end{array}$} & \multicolumn{2}{|c|}{ Inadequate Supervision } & & 6 & & & 1 & & & & & & & & & \\
\hline & \multicolumn{2}{|c|}{ Planned Inappropriate Operations } & & 4 & 2 & & & & & 1 & & & & & 1 & \\
\hline & \multicolumn{2}{|c|}{ Failed to Correct Problem } & & 4 & & & & & & & 1 & & & 1 & & \\
\hline & \multicolumn{2}{|c|}{ Supervisory Violations } & & 3 & & & & & & & & & & & & 1 \\
\hline \multirow{3}{*}{$\begin{array}{l}\text { Organization } \\
\text { al Influences }\end{array}$} & \multicolumn{2}{|c|}{ Resource Management } & & 9 & & & & & & & & & & & & \\
\hline & \multicolumn{2}{|c|}{ Organizational Climate } & & 2 & & & & & & & & & & & & \\
\hline & \multicolumn{2}{|c|}{ Organizational Process } & & 25 & & & & & & & & & & 1 & & \\
\hline
\end{tabular}

Keterangan :

- UP(Universalism vs Particularism); U (Universalism); P (Particularism)

- IC (Individualism vs Collectivism); I (Individualism); C (Collectivism)

- NA (Neutral vs Affective Relationship); N (Neutral); A(Affective)

- $\quad \mathrm{SD}$ (Specific vs Diffuse); S (Specific); D (Diffuse)

- $\quad$ AA (Achivement vs Ascription); Ac (Achivement); As (Ascription)

- $\quad$ TO (Time Orientation); SS (Sequence vs Synchronity); PPF (Past Present Future)

- $\quad \mathrm{IE}$ (Internal vs External); I (Internal); E (External)

Berdasarkan hasil identifikasi aspek budaya yang berhubungan dengan faktor penyebab kecelakaan, dapat ditemukan hubungan setiap lapisan HFACS dengan dimensi budaya dari Trompenaars. Sub lapisan Unsafe Acts - Decision Error berhubungan dengan Universalism vs Particularism, Individualism vs Collectivism, Neutral vs Affective Relationship, dan Achievement vs Ascription. Lapisan Unsafe Acts - Violations berhubungan dengan Universalism vs Particularism.

Lapisan Precondition for Unsafe Acts - Environmental Factors berhubungan dengan Internal vs External Direction. Adverse Mental States memiliki hubungan dengan dimensi budaya Neutral vs Affective Relationship, Achivement vs Ascription, Time Orientation, dan Internal vs External Direction. Crew Resources Management memiliki hubungan dengan dimensi budaya Individualism vs Collectivism, Specific vs Diffuse, Neutral vs Affective Relationship, dan Achivement vs Ascription. Seluruh lapisan Unsafe Supervision dan Organizational Influences berhubungan dengan dimensi Universalism vs Particularism. 
Namun dimensi budaya Universalism vs Particularism sub lapisan paling banyak ditemukan berhubungan dengan Organizational Process.

Setiap Negara dapat memiliki budaya yang berbeda. Sama halnya dengan Indonesia yang memiliki budaya yang berbeda dengan negara lainnya. Perbedaan budaya ini mendukung dugaan bahwa HFACS memerlukan modifikasi sebagai penyesuaian untuk aspek-aspek budaya yang belum terliputi oleh HFACS. Pada beberapa lapisan HFACS, aspek budaya telah tercakup didalamnya. Walau begitu terdapat pula lapisan yang memiliki indikator yang tidak spesifik sehingga patut diduga HFACS tidak mampu menggambarkan secara detail setiap budaya yang mungkin muncul. Sebagai contoh, HFACS yang pada awalnya dirancang untuk keperluan US NAVY diduga tidak mencakup budaya particularism mengingat Amerika Serikat sangat berbudaya universalism.

Lapisan unsafe acts - error - decision error memiliki banyak kemungkinan mengenai budaya apa yang mempengaruhi seseorang membuat keputusan namun budaya yang paling sering muncul adalah universalism vs particularism, individualism vs collectivism, dan asciption vs achievement. Aspek particularism dapat berpengaruh ketika seseorang membuat persepsi sendiri atas hal yang benar dan salah. Individualism berpengaruh pada pembuatan keputusan sendiri tanpa berdiskusi dengan rekan. Ascription dapat berpengaruh pada atasan yang merasa tidak percaya terhadap bawahan maupun bawahan yang tidak berani membetulkan tindakan atasan. HFACS awal belum meliputi ketiga budaya tersebut secara eksplisit. Pada lapisan ini dapat dilakukan penambahan indikator sub lapisan agar lebih jelas dan mencakup aspek budaya.

Budaya internal vs external direction mengenai lingkungan yang mempengaruhi performansi pun sering terjadi. Walau begitu budaya ini sudah cukup terwakilkan oleh lapisan environmental factors yang mencakup berbagai kondisi lingkungan yang dapat berpengaruh. Lapisan unsafe supervision banyak dipengaruhi oleh universalism vs particularism. Sebagai contoh lapisan supervisory violation mencakup kasus tidak adanya penegakan disiplin. Walau begitu, penyebab dari tidak adanya penegakan disiplin tidak dapat diketahui secara gamblang dengan HFACS. Misalkan saja adanya hubungan secara sosial antara pengawas dan pelaku sehingga pengawas membiarkan pelanggaran yang dilakukan oleh pelaku. Aspek particularism berpengaruh pada lapisan ini.

Pada lapisan organizational influences - organizational process, budaya particularism pada pengadaan pelatihan dan pembuatan prosedur atau peraturan yang tidak lengkap sangat sering ditemukan pada kasus kecelakaan. Particularism pada kasus ini adalah masalah modifikasi peraturan. Selain itu, budaya universalism vs particularism sering muncul di berbagai lapisan HFACS walau yang paling banyak adalah pada lapisan organizational process. Hal ini perlu dipertimbangkan lebih jauh untuk melengkapi HFACS awal. Pada lapisan unsafe supervision dan organizational process dapat dipertimbangkan untuk menambah sub lapisan baru yang berkaitan dengan budaya universalism vs particularism.

\section{Kesimpulan dan Saran}

Dari 53 kecelakaan yang diteliti, faktor manusia terlibat sebagai penyebab kecelakaan dalam 45 kecelakaan. Dengan kata lain, $84,91 \%$ dari kecelakaan yang diteliti melibatkan faktor manusia sebagai penyebab kecelakaan. Persentase lapisan HFACS yang terlibat dalam kecelakaan penerbangan yang diteliti adalah level Precondition for Unsafe Acts (34\%), Unsafe Acts (32 $\%$ ), Organizational Influences (19\%), dan Unsafe Supervision (15\%). Sedangkan 3 urutan sub lapisan HFACS yang paling dominan menjadi penyebab kecelakaan adalah Skill Based Errors (15,57\%), Organizational Process (12,30\%), Crew Resources Management $(9,43 \%)$.

Setelah dilakukan klasifikasi penyebab kecelakaan dengan HFACS, dilakukan pula identifikasi aspek budaya yang mempengaruhi setiap penyebab kecelakaan tersebut. Dapat ditemukan bahwa dimensi Universalism vs Particularism adalah dimensi budaya yang paling dominan sebagai budaya yang mempengaruhi penyebab kecelakaan. Urutan dimensi budaya berikutnya adalah Internal vs External Direction, Neutral vs Affective Relationship, Individualism vs Collectivism, Ascription vs Achievement, Time Orientation, dan Spesific vs Diffuse.

Pada HFACS awal, beberapa aspek budaya telah termasuk pada lapisan-lapisan tertentu seperti Precondition for Unsafe Acts - Personnel Factors - Crew Resources Management dan Precondition for Unsafe Acts - Condition of Operators - Adverse Mental States. Berdasarkan frekuensi kemunculan aspek budaya dan lingkup HFACS awal, lapisan yang perlu dipertimbangkan untuk dilengkapi dengan aspek budaya adalah unsafe acts - error - decision error, unsafe supervision, dan organizational influences - organizational process. Penelitian lebih lanjut diperlukan untuk mengembangkan HFACS awal menjadi HFACS yang sesuai dengan kondisi budaya Indonesia sehingga HFACS dapat diterapkan di Indonesia. Beberapa lapisan HFACS perlu dipertimbangkan untuk dimodifikasi dengan ditambahkan sub lapisan atau indikator sub lapisan perlu diperjelas. 


\section{Referensi}

[1] Dhillon, B. S., Human Reliability with Human Factors, Oxford: Pergamon Press. (1986).

[2] Direktorat Jenderal Perhubungan Udara, Statistik Angkutan Udara. Diambil dari http://hubud.dephub.go.id/?id/produksi/index/filter:category,1;tahun,0;bulan,0;airport,0. (2013)

[3] Direktorat Jenderal Perhubungan Udara, Tugas Pokok, Diambil dari http://hubud.dephub.go.id/?id/page/detail/13. (2013)

[4] Hofstede, G. \& Hoftstede G.J., Cultures and Organizations - Software of the mind, Revised and Expanded 2nd Edition, New York: McGraw-Hill USA. (2005)

[5] Izazaya, Z., Kajian Taksonomi Kecelakaan Kereta Api di Indonesia Menggunakan Human Factors Analysis and Classification System (HFACS), Tesis Program Studi Teknik dan Manajemen Industri, Institut Teknologi Bandung. (2012).

[6] Jambak, M. I., Perancangan Petunjuk Pelaksanaan Investigasi Kecelakaan Menggunakan Metode HFACS, Tesis Program Studi Teknik dan Manajemen Industri, Institut Teknologi Bandung, (2011).

[7] KNKT, Analisis Data Kecelakaan dan Investigasi Transpotasi Udara Tahun 2007-2011, Diambil dari http://www.dephub.go.id/knkt/ntsc_aviation/baru/Publications/Media\%20Release\%20Udara\%202011.pdf, (2011).

[8] Li, W.C., Harris D., Chen A., Eastern Minds in Western Cockpit: Meta-Analysis of Human Factors in Mishap from Three Nations, Aviation, Space, and Environmental Medicine, 78 (4), Section 1, (2007).

[9] Paletz, S.B.F., Socializing the Human Factors Analysis and Classification System: Incorporating Social Psychological Phenomena Into a Human Factors Error Classification System, Human Factors, 51 (4) (2009), 435-445.

[10] Putri, A., Evaluasi Kecelakaan Pesawat Terbang Sipil di Indonesia dengan Menggunakan Metode Human Factor Analysis and Classification System (HFACS), Tugas Akhir Program Studi Teknik Industri, Institut Teknologi Bandung, (2011).

[11] Sanders, M.S. \& McCormick, E.J., Human Factors in Engineering and Design, New York : McGraw-Hill Inc, (1992).

[12] Shappell, S.A. \& Wiegmann, D.A., Applying Reason: The human factors analysis and classification system (HFACS), Human Factors and Aerospace Safety, 1, (2001), 59-86.

[13] Shappell, S.A. \& Wiegmann, D.A., A human error analysis of general aviation controlled flight into terrain accidents occurring between 1990-1998, Washington DC: Federal Aviation Administration, Office of Aviation Medicine. (2003).

[14] Shappell, S.A. et al., Human Error and Commercial Aviation Accidents: An Analysis Using the Human Factors Analysis and Classification System. (2007).

[15] Trompenaars F. \& Hampden-Turner C., Riding The Waves of Culture: Understanding Cultural Diversity in Business, London : Nicholas Brealey Publishing, (1997).

[16] Wickens, C.D., Lee, J., Liu, Y. \& Becker, S.G., An introduction to human factors engineering, New Jersey: Pearson Education, Inc. (2004).

[17] Wiegmann, D. A., \& Shappel, S. A., Human Error Perspectives in Aviation. The International Journal of Aviation Psychology, 11(4), (2001), 341-357.

[18] Wiegmann, D. A., \& Shappel, S. A., A Human Error Approach to Aviation Accident Analysis, Burlington: Ashgate Publishing Company, (2003).

[19] Wurmstein, A., DOD HFACS - A Mishap Investigation and Data Analysis Tool. Department of Defense Human Factors Analysis and Classification System, (2003), 1-12. 